DePauw University

Scholarly and Creative Work from DePauw University

Spring 2011

\title{
Resilience and Community in the Age of World-System Collapse
}

Glen David Kuecker

DePauw University, gkuecker@depauw.edu

Thomas D. Hall

DePauw University

Follow this and additional works at: https://scholarship.depauw.edu/hist_facpubs

Part of the Sociology Commons

\section{Recommended Citation}

Kuecker, Glen David and Hall, Thomas D., "Resilience and Community in the Age of World-System Collapse" (2011). Nature and Culture. Vol. 6; No. 1. (2011): 18-40. This is a post-peer-review, precopyedited version of an article published in Nature and Culture Vol.6, No.1, pp.18-40. The definitive publisher-authenticated version is available online at: http://berghahn.publisher.ingentaconnect.com/ content/berghahn/natcult/2011/00000006/00000001/art00002

This Article is brought to you for free and open access by the History at Scholarly and Creative Work from DePauw University. It has been accepted for inclusion in History Faculty publications by an authorized administrator of Scholarly and Creative Work from DePauw University. 


\title{
Resilience and Community in the Age of World-System Collapse
}

\author{
Glen David Kuecker and Thomas D. Hall
}

\begin{abstract}
In this essay we explore how humans might face systemic collapse and/or entry into a dark age through forms of community resilience. We also note that nature, types of communities, and degrees of resilience differ in core, peripheral, and semiperipheral areas of the contemporary world-system. Core or global north or first world communities have all but disintegrated due to neoliberal policies. However, communities in peripheral and semiperipheral areas are more emergent, and more resilient. These areas are most likely to have or to creatively develop strategies to overcome global collapse. We further argue that social scientists need to develop new definitions of community that go beyond contemporary conceptualizations.
\end{abstract}

\section{KEYWORDS}

community, complex adaptive systems, complexity, globalization, neoliberalism, panarchy, systemic collapse, world-systems analysis

\section{Introduction}

Thomas Friedman, in an 8 March 2009 New York Times op-ed, stated that in the year 2008 the global community "hit the wall." His editorial is significant because one of the prominent American cultural observers publicly recognized that we live in an era when multiple, large-scale, interconnected structural crises have pushed the global system to the threshold of catastrophic collapse. While Friedman's pronouncement carried with it a multitude of false assumptions and a disturbing depth of amnesia about ideas he once promoted, it does stand as a marker in public discourse. Friedman's $(2008,2009)$ awakening is not news to many of us. His "wall," after all, is nothing more than a popular articulation of Chew's $(2002,2005,2007,2008)$ idea of recurrent "Dark Ages," the proposition that periods of overshoot provoke periods of deep crisis that then allow for ecological recovery. The Dark Ages argument highlights a key point in Friedman's editorial, one that was most likely missed by "arrogant elites." Once we 
have hit the wall and the threshold of collapse is crossed, our ability to reverse course is thwarted by the deeper reality of collapse: it forces change on society.

This essay considers humanity's prospects as we enter into an era defined by transition to catastrophic collapse. It approaches the topic through a synthesis of perspectives. We bring world-system theory together with complexity theory in order to understand how we might conceptualize ways to enhance our ability to survive the shocks of multiple, interconnected, large-scale, synchronous crises. We focus attention on the importance of community in building system resilience, and aim to understand the potential paths that divergent forms of community might take as our global system heads deeper into crisis. We begin with introductory statements about the world-system, complexity, and community. We then discuss community from the perspective of the system's core, from the periphery, and from the semiperiphery. We end with a consideration of humanity's possible future paths.

Two central features define the system organizing the modern world. The first is the world-system's uneven development through time and space, which results in a geography of core, periphery, and semiperiphery. While neoliberal, corporate globalization has enhanced the hybrid distribution of core, periphery, and semiperiphery so that each carries elements of the others within it, neoliberalism has also deepened the uneven development of the world-system, increasing the distance between core and periphery while also enhancing the size and importance of the semiperiphery (Robinson 2004).

The second feature is the extraordinary way modernity has constructed high levels of complexity throughout the world-system. Understanding this complexity at a time when the world-system is highly stressed is a daunting task for the social sciences. In this essay we pursue the view that our world operates within a four-step cycle of change that governs complex adaptive systems: exploitation, conservation, release, and reorganization (for details on this process of change, see Salt and Walker 2006; Gunderson and Holling 2002). ${ }^{1}$

The exploitation phase occurs when a system grows rapidly toward increasing connectivity and order. The successful adaptations within this phase become the system norm, and mark the transition to the conservation phase. Using the successful adaptations, during the conservation phase the system needs to find increased levels of efficiency in order to reproduce. Over time, the need for greater efficiency 
makes the system rigid and leads it to an unsustainable state of overshoot, which is when a system, because of the need for continual growth, deploys creativity and innovation in the attempt to maintain it beyond normal limits of reproduction (Clark 2002: 114). Rigidity and overshoot make the mature conservation phase prone to disruptions that can tip it into the release phase. In the release phase, the system's propensity for disorder pushes it to a bifurcation point between a path of innovative system renewal or catastrophic collapse. If it encounters collapse, the system moves to the reorganization phase. At this point, the system is in a chaotic state where uncertainty and novelty rule. Eventually, innovation moves the system back to the first step of the cycle. As a complex adaptive system, modernity has long passed its exploitation cycle, and, depending on one's interpretation, it is either in the climax of the conservation phase, in a state of extreme overshoot, or has crossed the threshold into the release phase.

Complex adaptive systems are defined by panarchy, which describes the linkages between the adaptive cycles of small, medium, and large-scale systems. The modern world-system's scope and scale means its iteration of panarchy is immense-neoliberal globalization has linked almost all global systems - which increases the chance that multiple critical systems will reach their release phase at the same time. Such systems are also very prone to synchronous failure, which are often catastrophic events. The scales of panarchy correlate with the world-system's uneven time-space distribution of core, periphery, and semiperiphery. This correlation means that threshold transitions from conservation to release, as well as entrances and departures from bifurcation paths, will happen at different times, places, and intensities (Salt and Walker 2006; Gunderson and Holling 2002; HomerDixon 2006; Clark 2002). We argue that much of the periphery and semiperiphery are currently at the gates of bifurcation and that some have already passed into collapse, while the core remains in a state of extreme conservation phase overshoot.

The key to surviving catastrophic systemic collapse is to mitigate the severity of the release cycle by enhancing system resilience. HomerDixon states: "We can keep future breakdown constrained-that is, not too severe-by making our technological, economic, and social systems more resilient to unexpected shocks" (2006: 20, emphasis in original). A system is resilient when it is able to absorb shocks that threaten synchronous failure and collapse. The more complex systems become, especially in the conservation phase, the less resilient they are (Salt and Walker 2006; Homer-Dixon 2006). 
In part, the loss of resilience happens because a system's pursuit of efficiency during the conservation phase becomes structurally locked into positive feedback loops that make it less adaptable to new environments. Contrary to the celebratory "end of history" narratives of the neoliberals (Friedman 2000; Fukuyama 1989), our current age of globalization, which is defined by a free market-driven positive feedback loop of capitalist efficiency, has pushed humanity beyond the tipping point of sustainability and into a precarious state of extreme loss of resilience (Kuecker 2007). In contrast to neoliberal thinking about community, which replaces the idea of the "public" with fragmented communities of individual self-interest, the notion of community as a collective commons is an important feature of resilience. Homer-Dixon explains: "And we've forgotten, too, that resilience is a 'public good' - something in whose benefits everyone shares, whether or not they pay for it. As with any public good, whether national defense or fire protection, if the government doesn't intervene, everyone tends to wait for someone else to pay" (2006: 286). Reconstituting community is key for enhancing system resilience.

The conservation phase's relentless pursuit of efficiency led to global neoliberal economic restructuring starting in the early 1980s, what we now all know as "globalization." The process featured privatization and austerity programs that radically altered the state's relationship with society and the biosphere. ${ }^{2}$ The "post-social" outcome left large sectors of society disconnected from the state and from formal politics (Rose 1996, 2008). The conservation phase's assault on society has been brutal for many individuals, families, and communities, especially the billions who constitute the global majority throughout the periphery and semiperiphery.

Many people, of course, resisted neoliberalism. The conservation phase's drive for efficiency gave rise to anti-neoliberal social movements, which filled the post-social void during the 1990s. Amidst the ashes of the post-social phase, new actors began reconstituting community, often in new and creative ways (Kuecker, Stahler-Sholk, and Vanden 2008). We argue that through the struggle against the conservation phase's neoliberal globalization, newly articulated communities constitute critical seeds of resilience necessary for navigating and surviving the challenges of complex system adaptation.

In social science thinking, the "return to community" idea has taken many forms. Our approach is informed by the collaborative research undertaken by Kuecker with the Globalism Research Centre (GRC), RMIT University, Melbourne, especially the scholarship gener- 
ated by members of its sustainable community project. The GRC approach builds from the work of Bauman (2001), Delanty (2010), Massey (2005), and Rose (2008) to argue that in times of change, people turn to community for security anchored in a collective sense of belonging. Kuecker, Martin Mulligan, and Yaso Nadarajah (2010) have conducted field research in Australia, India, Sri Lanka, Malaysia, Papua New Guinea, Guatemala, Mexico, and Ecuador, with an eye toward the relationship between community and resilience during global crises. They find that resilience results from how people navigate between multiple forms of community, especially as they increasingly contend with the forces of globalization and the onslaught of crisis that we associate with the spent conservation phase tipping into the release phase.

The relationship between community and resilience is heavily influenced by the historical evolution of the world-system. Due to the system's uneven development, the relationship between community and resilience is not the same throughout the world: it is different in the core, periphery, and semiperiphery. In the core, community is primarily an emergent property that may come to fruition during the release phase, while it is currently an existing property in the periphery, especially, but not exclusively, among indigenous populations. We argue that the semiperiphery is where the hybrid of the core's emergent properties and the periphery's existing properties is most active, which results in the semiperiphery being a hotbed of social change and system transformation. We argue that the hybrid nature of the semiperiphery challenges the typologies we have for thinking about communities. We approach this argument by identifying the informal economy as a key form of semiperipheral social behavior. While it is integral to reconstituting semiperipheral communities, the informal cycle most likely cannot serve a similar role in the release phase.

\section{Core as Emergent Property}

The core has experienced a near-total destruction of community. While it has been a centuries-long process, the final death of community was accomplished with corporate-driven, neoliberal globalization that has resulted in the "post-social." With the post-social, according to Rose (1996), the object of government shifted from the collective of society to the individual acting within a diversity of highly fragmented, atomized communities of narrowly-shared self-interests. Putnam's Bowling 
Alone (2000) captures post-social dysfunctionality by showing how social capital has been undermined by affluence. In Ecology of Fear, Davis (1998: 360-422) illustrates how a destroyed commons drives Americans deeper into social pathologies that generate a culture of fear and lead people to embrace apartheid-like practices of walled communities, increased policing, more penetrating technologies of surveillance, and ever more criminalization of the marginalized (Kuecker 2004).

The core remains deeply entrenched in the community-destructive forces of modernity in its late conservation phase. The turn to the community will require a breaking free from modernist mentalities, and requires a profound paradigm shift in the power system, one that most likely will play out in the longue durée and not through the actions of reform-minded Western leaders, assuming they can push through even the mildest reforms. Our argument extends the several critiques of developmentalism (Escobar 1995; Esteva and Prakash 1998; Slater 2004) into consideration of system resilience in systemic collapse. For many, this is a counter-intuitive argument: contrary to the modernization paradigm, which finds the periphery in need of repair, this argument finds the core continuing to destroy community while thinking it is saving the world.

Many analysts of our current global predicament have reached the conclusion that solutions to vexing problems require a drastic scaling back of humanity's complexity. From a variety of positions, ideas, and proposals, they all call for a return to community. Anderson and Ray (2000), Brown (2006), Korten (1999, 2006), and McKibben (2007) all maintain that small, local, decentralized communities must be the defining features to human organization if we are to prevent a catastrophic collapse. These ideas share common ground with radical alternatives to the social, political, economic, cultural, and ecological hegemony of the core's conservation phase. Albert's (2003) participatory economy, Friedmann's $(1987,1992,1998)$ radical planning, Arato and Cohen's (1992) civil society, and the sustainable justice of Agyeman (2005) show that there is no shortage of vision for how to escape the destruction of the commons and build a more just world.

Bioregionalism perhaps best represents these ideas. As discussed by Carr (2004: 16), "Bioregionalism is a philosophy with values and practices that attempt to meld issues of social and economic justice and sustainability with cultural, ecological, and spiritual concerns." In this vision, "democratic social and cultural change take place primarily in the sphere of civil society" (Carr 2004: 16). Carr sees it as a "move- 
ment" that "has developed a praxis of social change that challenges the modernist construct of 'economic man' upon which neoliberal globalization rests. Civil society theory, like bioregionalism, questions neoclassical economic constructs that deny/negate broader enlightenment conceptions of humans as social, communicative beings" (2004: 16). Through their radical "critique of conspicuous consumption," and subsequent place-based ecological ethic, bioregionalists experience spiritual transformations that add to the civil society mix. Carr explains, "Reductions in consumption and the demanding life work of organizing for sustainable social change have been supported - in the experience of many bioregionalists - by certain emotional/spiritual benefits of bonding both with other humans and with the natural world in particular places" (2004: 16-17). The convergence of spiritual and political produce what Carr defines as "ecosocial capital," the "vital bonding process" of "synergistic energy involving spiritual feelings of joy and love" (2004: 17).

These visions of return to community are important for increasing our chances of a positive turn at the bifurcation point in the release phase. Yet, we find several critical problems with the return to community concept. They tend to be one-size-fits all propositions that can be plugged into any given situation in time and space without regard to hegemonic barriers. Ideas like bioregions are part of minority trends that hardly constitute social movements. These visions of community face nearly insurmountable odds of realization. They will require radical change in a very short period of time, and such change is not likely to happen before catastrophic collapse forces such change on the core.

Despite Sherry Ruth Anderson and Paul Ray's (2000) argument that a paradigm shift toward community is within the core values of the American Dream - an argument advanced by David Orr and the Focus the Nation group that is attempting to construct a grassroots movement from above to combat climate change-the fundamental reality is that bioregions are too few and too isolated to serve as transformative mechanisms within the core during its conservation phase. Given the reality of intensified paths of overshoot, the call for a return to community appears to be a new age dreamer's fantasy (Kuecker 2004). Likewise, we can have a plethora of Loeb's (1999) engaged community activists who undergo life-transforming experiences that shake them into social activism, but these citizens are miniscule in number when facing the magnitude of the task of transforming the core into a society and culture prepared to leverage the release phase's 
bifurcation moment. The idea that the core, with all of its high technology, human capital, and ingenuity, will either obviate or surmount the challenges posed by the release phase is deeply rooted in the modernist vision of progress embedded in the conservation phase's epistemologies. It is also one that blinds itself from being able to see "progress" as a driving factor to collapse. With ideologies like U.S. exceptionalism framing our understandings of the current global predicament, any proposition that the shift from conservation to release phase will be smooth is naive, misguided, and potentially dangerous. Being stuck with our faith in modern progress-and potentially facing a reality where the core can not escape the modernity that created it-becomes the core's equivalent to the periphery and semiperiphery's post-colonial problematic. The inability to transcend modernity appears to be the defining feature tainting the ideas and policies created to contend with the problems of the twenty-first century.

The core's resilient community, if it does appear, will come as a product of the "edge of chaos," especially the process of emergence within the release phase. During the 1980s, an odd assortment of scientists, economists, and social scientists worked at the Santa Fe Institute (SFI). They sought to understand complexity, especially the place of the "edge of chaos" in systems analysis. Complexity, according to Waldrop's (1992) analysis of the history and people behind SFI, is seldom a system of stable equilibrium. It hovers near the "edge of chaos," always proximate to system-changing thresholds. Complexity is defined by the near lack of coherence and predictability, as if it were overrun by all the possible computations and permutations generated by a multiplicity of interacting parts, sub-systems, networks, and systems.

Taylor's cultural exploration of the "moment of complexity" adds to this analysis. He explains that "all significant change takes place between too much and too little order" (2001: 14). When there is too little order in a system, it can approach the edge of chaos, when the system can break down, fail to reproduce, or otherwise disintegrate. But, when there is too little order within the system, the need for ingenuity is augmented. These types of "edge of chaos" moments, Taylor argues, are often times of great creativity driven by the need to resolve serious problems or limitations within the system. When systems reach the bifurcation point, the innovations necessary for emergence into an adaptive, self-reproducing system are often discovered or implemented. For Taylor, "emergence" is closely related to the "edge of chaos," a moment of creativity when one system tips to something new and different. 
The relationship between resilience, emergence, and community is fundamentally a problem of structure and agency. Wallerstein offers insight on this point:

I say that when systems are functioning normally, structural determinism outweighs individual and group free will. But in times of crisis and transition, the free will factor becomes central. The world of 2050 will be what we make it. This leaves full reign for our agency, for our commitment, and for our moral judgment. It also means that this period will be a time of terrible political struggle, because the stakes are much higher than in so-called normal times (1998: 64).

Wallerstein's emphasis on agency appears to depend upon modernity's departure from the "normal times" of the conservation phase and its entrance to the release phase. The creation of resilient communities in the core is predicated on radically changed structures that allow human agency to make history. In the release phase, the structural conditions are radically altered if not eliminated, and from it emergent properties like bioregions may flourish. For bioregions to transform the core, however, a departure from the conservation phase has to take place, and that means radical structural change.

The timing of the core's emergent properties during the bifurcation moment is important. Systems theorists like Homer-Dixon (2006) and Meadows, Meadows, and Randers (2004) maintain that there is often a lag time in people's ability to understand processes of change, and often such understandings are only possible with historical hindsight. Often, when structural change compresses the relationship between time and space, people are not fully aware of the change and its contours, functions, direction, and meaning. It is "noise" in process of becoming "information" (Taylor 2001: 99-123). The delay in constructing master narratives - Taylor's "becoming information" about structural change means we do not fully understand processes that fundamentally change our world as those changes happen.

\section{Periphery as Existing Property}

Hall and Fenelon (2004, 2008, 2009; Fenelon and Hall 2008) argue that indigenous communities demonstrate how community can survive within and despite the modern world-system. These examples offer important insights about how to conceptualize community as a key to human resilience in a world-system that is either on the threshold or in the release phase, and the importance of the periphery to re- 
silience. Hall and Fenelon show that surviving indigenous communities are not "living fossils." Rather, they are examples of how various peoples have adapted to and adopted from the modernizing efforts of the core even while maintaining their own values and practices, key among them a strong sense of community and institutions that promote collective good.

We caution, however, that it is important not to reify and romanticize indigenous experience. We do not offer it as a blueprint for change to be copied by the core in some delusional "Dances with Wolves" or "Avatar" fantasy. Rather, indigenous experiences are models of alternatives to the neoliberal conservation phase. We maintain that the experience of indigenous people with modernity offers them advantages over the core during the release phase's bifurcation point. Looking for likely bifurcation survival candidates, we look to indigenous peoples, who have - at least those who survive into the twentyfirst century - maintained essences of pre-state senses of community and ways of acting collectively to a remarkable degree that have been lost everywhere else. This is due to several factors operating at different scales. First, they are small, face-to-face groups, so secrets and ignorance are rare. Second, they have often been in fringe areas, where they have not received excessive state attention. Third, they often present neoliberal capitalist states with a dilemma: to deny autonomy and sovereignty to indigenous groups simultaneously undermines the state's claims to autonomy and sovereignty (Wilmer 1993; Hale 2004; Hall and Fenelon 2004, 2009). Fourth, these groups have been remarkably creative in maintaining their core values even while challenging some features and adopting others of modern states (for detailed examples see Pickering 2000a, 2000b).

We explicitly reject the various contemporary social science definitions of community, especially the neoliberal conception of community as a group of individuals acting together toward a shared interest. Rather, we propose using the range of models used by many different indigenous peoples (Hall and Fenelon 2009, especially Ch. 2). These communities are in some sense "organic" or "natural," albeit not in the way Durkheim used the term organic. By this we mean they have grown over extended periods of time and are well-adapted to their homelands (see too, Bodley 2003). Some insights into how indigenous peoples, in both the modern world and ancient worlds, adapted and adopted practices from outsiders can be seen Kardulias's discussion of "negotiated peripherality," which he defines as "the willingness and ability of individuals in peripheries to determine the con- 
ditions under which they will engage in trade, ceremonial exchange, intermarriage, adoption of outside religions and political ideologies, etc. with representatives of expanding states" (Kardulias 2007: 55).

This concept suggests that peripheral peoples adopt or reject symbols, artifacts, foodstuffs, and behaviors selectively after they assess the value of these items. Typically they choose options based on perceived benefits: (1) adopting some new form; (2) retaining an old or traditional practice or object while simultaneously rejecting the foreign version; or (3) crafting some mixture of the traditional and external which they amalgamate into a hybrid. All three may have both short-term and long-term goals. Short-term consequences can often be judged with some degree of certainty. However, there may be unintended long-term consequences.

Peripheral societies, especially indigenous communities, are considerably if not totally "off the grid" of modernity. This point is essential for understanding systemic resilience because peripheral communities provide the most space for autonomy to thrive, especially when compared to communities in the core. Autonomy is critical for sustainable communities of the twenty-first century. Autonomy might best be understood by thinking about how it answers the most basic question: who has the power to decide about all changes. The autonomous answer is the fundamental revolt against the conservation phase's concentrations of power in the domains of a few individuals, institutions, corporations, and the state. Autonomy is a revolutionary proposition, one fundamentally opposed to the realities of the twentyfirst century's conservation phase. Autonomy aims to destroy concentrations of power and replace them with horizontal forms of democracy, a radical, true, participatory democracy that provides a voice to everyone in the decision-making process. Autonomy penetrates every domain of life, becoming a way of life that connects community to land, environment, religion, and language in a complex web of economic, social, and political relations. Autonomy's focus on the reconstitution of community answers the question of "who decides" as communal control over land use, water rights, oil, minerals, and trees, as well as indigenous knowledge about the environment. Deeper, autonomy is the ways of living, being, thinking, and seeing that cannot be turned into commodities for the capitalist market. Autonomy means the community decides what to do with resources, not the neoliberal state, not the World Bank, not the United States Department of Treasury, and not consumers in the first world. Autonomy constitutes a domain of sovereignty that negates the conservation phase's 
post-social order (Díaz-Polanco 1997; Esteva 1999; Hernández Navarro and Herrera 1998; Aída Hernández Castillo and Mattiace 2003; Mattiace 2003).

\section{Semiperiphery and Informality}

The semiperiphery serves as a link between the core and the periphery. It is the structural mechanism that joins complicated geographies of the periphery's small-scale systems to the larger scale systems of the core. The semiperiphery makes the extraordinary levels of modernity's panarchy possible. While the linking function is essential for the conservation phase's continual reproduction, it also is the key for what transpires in the release phase, especially at the bifurcation point when creativity is at a premium. Informality enables the semiperiphery to play its role in panarchy, because informality operates through the semiperiphery's linkage between periphery and core, and echoes its role in conservation and release phases.

In the back cycle of systemic release and reorganization, the semiperiphery has a leading role because it has always been a dynamic space for social change and system transformation (Chase-Dunn 1988, 1990; Chase-Dunn and Hall 1997: Ch. 5). These features correspond to the release phase's premium for creativity and innovation. Chase-Dunn and Hall illustrate three key points for how and why the semiperiphery is a seedbed for systemic change. First, semiperipheral states and/or societies often are sufficiently knowledgeable about core social processes and structures to capture ideas from them, yet are also sufficiently autonomous from core societies not to be overcommitted to the structures and processes of the core's conservation phase. As the system shifts to the release phase, some semiperipheral areas will avoid collapse because of this autonomy, while the core will need to change radically or face total collapse.

Second, the autonomous feature of semiperipheral regions distances them from the hegemonic scope of the center's conservation phase, which allows the semiperiphery to have greater latitude in social, political, economic, and cultural experimentation, innovation, and creativity. This latitude constitutes a major advantage in the release phase because it allows emergent properties to thrive.

Third, Chase-Dunn and Hall emphasize the importance of technological innovation within the semiperiphery, which often involves selective borrowing from the core's successes and a liberating ability 
to jump stages of technological development. Borrowing and stagejumping free the semiperiphery from the core's deep rigidity within the conservation phase, which help make it more resilient to disruptive shocks.

The informal sector helps to create the socially-transformative quality of the semiperiphery. In the conservation phase's wasteland of destroyed communities, informality first fills the post-social void as an existing property and then begins the process of emergence by reconstituting community. The release phase result, however, is not community as many might fancy it, but a set of transformed social relationships. The transformation happens because of the extreme distortions in the collective shared sense of belonging caused by the conservation phase. These distortions carry over into the release phase, and influence the outcome of the bifurcation point. In this way, the "informal" is not the old, conservation phase norm for what constitutes a community, which is, following the rigidity of the conservation phase, very formal, but instead an entirely new way of being social. This process most often involves highly marginalized persons from the global south (better phrased, perhaps, as the global majority), who either leave the periphery for the semiperiphery or are already surplus population in the semiperiphery. Once in the semiperiphery, informal actors are the social forces driving its social transformative feature.

Taking from Hart's $(1970,1973)$ pioneering work on the informal sector, and the International Labor Office (1972), we define informality as work outside the formal labor market. We extend this definition to mean activity that avoids government regulation and taxation, which, for some, further extends to illicit, underground economies or black markets. In the conservation phase, the informal sector has a dual quality of system resistance and reproduction. Since a defining feature of the conservation phase is rigidity produced through the relentless pursuit of efficiency, especially through neoliberal restructuring, the informal sector is constituted in opposition to the formalities of the cycle. Neoliberal brutalities generate an ever-growing informal sector, especially as the post-social destroys communities. In Latin America, for example, neoliberal reforms of the 1990s and 2000s resulted in dramatic growth of the informal sector. It provided $44.3 \%$ of Argentine employment in 2004, 59.9\% in Colombia, and $62.9 \%$ in Paraguay (Robinson 2008: 243). "Informal economies," according to Henry, "emerge from the contradictions of capitalism, but they are simultaneously supportive and undermining of capitalism, as that system is of them. Put simply, informal economies both are shaped by 
and shape the wider political economy in which they are set" (1987: 138). Modernity in the conservation phase seeks to incorporate, regulate, and control the informal sector, while the informal sector pushes back against the rigid rule sets of the conservation phase. The creative energy of informality stimulates the conservation phase's urge to control, which provokes further innovation and creativity by the informal sector as it strives to escape from the repressive control of the conservation phase.

Despite the tensions of the conservation phase-informality game of cat and mouse, neoliberals are enchanted by the informal sector. Their adoration is a marker of informality's importance in the conservation phase as it attempts to manage the increasingly unmanageable behavior of a system in extreme overshoot. De Soto (1989) and Sen (1999), for example, marvel at the creative energy of informality. For them, informal actors represent the glory of raw capitalism, the living proof of the truth to Adam Smith's claim of the human propensity to truck, barter, and trade. All that is needed to lift informal actors out of their often-desperate human condition is the rule of law, one that recognizes the sanctity of private property, which, of course, is the mechanism that destroyed the commons and generated informality in the first place.

The raw energy of informality also carries a dual relationship between existing and emergent properties. As a necessary part of the conservation phase, informal actors are an existing property. Yet they exist in a constant state of agitated emergence resulting from the conservation phase's attempt to control and regulate. They are never stable, existing on the edge of chaos all the time. The dual qualities of informality means informal actors are bridges between multiple systems, and allow for their borders to be crossed, especially between the geographical and scale range between periphery and core. As panarchy's social agents, informal actors traverse from core to periphery, making them constitutive of the semiperiphery's place and function within the world-system.

Street vending, migration, and urban slums are three examples of informality for our analysis of the semiperiphery. In each case, informality constitutes a pathway for social actor mobility within and between the periphery, semiperiphery, and core. Informality provides entrance into the system, despite the high levels of marginalization present amongst vendors, migrants, and slum dwellers. The mobility of informality is part of the emergent property characteristic of semiperiphery. 
Throughout the semiperiphery, billions of people gain economic subsistence as common street vendors. On blankets, folding tables, or by hand they peddle sunglasses, cigarettes, chewing gum and candy, screwdrivers, hammers, and wrenches, cell phones, batteries, books, flowers, blue jeans and shirts, hats, pirated movies and music, suitcases and backpacks, kitchen utensils, laundry soap, and radios. From their stalls, stands, and push-carts, vendors sell coffee, prepared fruits, sandwiches, Coca-Cola and chips, fried fish and chicken, and a variety of animal parts. Street vendors supply and feed a huge percentage of global humanity every day, are essential to system reproduction, and are the guts to everyday exchanges of global capitalism. Yet, their informality means they exist external to the system's mechanisms of regulation, control, and taxation. Informality means they have yet to be brought into the destructive power of Wal-Mart, and constitute a negation of corporate-driven neoliberal globalization, while also being necessary for its daily reproduction. Street vending, similar to urban slums, constitutes a pathway into the system, a means to become formal sector actors (Cross 1998, 2000; Illy 1986).

Globalization has enhanced the flows into various global diasporas. Undocumented migrants operate in a double world of fragmented regimes of labor and citizenship (Salter 2008); their labor makes them both a fundamental part of global capitalism and at the same time part of a shadow world of illegal citizenship (Bacon 2008; Inda 2006). Similar to vendors, migrants are key components to system resilience not only because they provide the cheap labor necessary for the conservation phase's process of capital accumulation, but also because migration allows rural communities to absorb the shocks to subsistence agriculture caused by the conservation phase's global free trade regimes. The cycle's relentless push for efficiency - the externalized costs of the post-social - is carried by the resilience of migrant labor. Throughout the semiperiphery, remittances from migrant workers are consistently the second- and third-highest contributors to the gross national product of their native countries, and in many cases, their work is crucial for the survival of the state. Though an existing property within the conservation phase, migrants are also emergent properties, especially because they mobilize financial and social capital in constructing complex transnational networks that weave together panarchy's webs of interlocking systems (Durand et al. 2002). Some scholars argue that migrants are creating new forms of transnational citizenship and community that are liberated from the confines of the nation-state and a geographically bounded practice of community 
(Cohen 2004; Fox 2005; Stephen 2007). Communities disarticulated from the modern boundaries of the nation-state are perhaps a glimpse at future forms of social behavior in the release phase.

There is a tight correlation between the informal economy and the social practice of urban slums, which we find to be one of the semiperiphery's clearest examples of system emergence and resilience. Davis (2006) shows that billions of people live in urban shantytowns. These people represent the classical pattern of emergent properties (see Johnson 2001). Not unlike ant colonies, where the action of individual ants takes on a collective logic, slums are characterized by a spontaneous, unregulated organizational pattern. The organization often supplies the basic requirements of social reproduction despite the lack of services that comes with the rationalized efficiencies of the conservation phase's neoliberal marginalization. While the cycle generates the slums at disturbingly high levels, it frets over controlling their emergence by formally incorporating them into the urban system. The conservation phase's impulse to control and regulate slums makes them similar to street vending and migration. Slums are characterized by movement and a logical expression of emergence, especially the movement of people from the hyper-marginalization of the periphery into the semiperiphery and toward systemic inclusion of the core's vested citizens. This social mobilization of billions of people constitutes one key area of semiperipheral social transformation.

A key component to the idea of informality is how it permeates everyday life practices that constitute community. Gaughan and Ferman, for example, state: "Thus we can see informal activities as providing a necessary part of the force of social cohesion, important in the definitions of kin and community." They find that networks generated by informality carry "a social ethic" where "members are protected from total and abject economic failure." They continue, "A well-integrated community resists allowing one of its own to fall into truly intolerable economic circumstances and will often send forth its own informal safety-net. This is particularly observable in disadvantaged communities where very scarce resources must be shared in order to ensure the survival of the network" (1987: 21). The communityforming consequence of neoliberal exploitation and marginalization is shown by Zlolniski (2006), who sees the promise and limitations of community organizing for migrants who work in the informal economy in Silicon Valley.

Informality will become greater as we move deeper into the twentyfirst century. It will be produced by the persistence of the dying con- 
servation phase, but even more so by the chaos and disorder - the informalization - of the release phase. Informality thus offers something of a glimpse at the future. Slums, vendors, and migrants all bring remarkable survival skills defined by high levels of ingenuity, adaptability, hard work, and perseverance that were all acquired from the brutalities of the conservation phase. These skills are at a premium in the release phase, especially at the bifurcation point. It is unclear, however, what happens to informality if the release phase turns toward catastrophic collapse. Slums, vendors, and migrants are deeply interconnected and implicated in the conservation phase, so much so it is hard to argue that they can have an existence that is not defined by their informality.

\section{Conclusion: Three Paths to the Future}

Entering the release phase, we urgently need to take measures to enhance the resilience of human society. We maintain that community is key for resilience. Yet we also argue that as we enter the new release phase, community and resilience are different in the core, periphery, and semiperiphery. We find two types of community within this spatial differentiation: emergent properties in the core and existing properties in the periphery. We find the dualities of informality to be an important area for theorizing semiperipheral communities and their role in the release phase.

Our analysis suggests that there are many possible paths into an uncertain future, but three major directions appear most likely. The first offers a continuation in our faith in modernity and its conservation phase, especially its paradigm of science and technology, which many have shown to be falsely grounded (Berry 1988; Korten 1999; Homer-Dixon, 2000). We argue that the first path is least likely to generate the resilient communities that are desperately needed.

The second path of non-capitalist, autonomous, small-scale, subsistence communities has demonstrated amazing resilience in a harsh world, one to a world that the conservation phase has often attempted to eliminate. We find that this path is most likely to endure the "perfect storm" of systemic collapse. We find these communities to be most common in peripheral areas, especially within indigenous groups who have practiced them since the first counting of their days. They are exceptionally scarce in the core. Lacking these communities in 
the core and semiperiphery, the prospects of averting the bifurcation point's catastrophe are slim.

The third path generated in semiperipheral areas has two possible outcomes. First, we have shown that its informality is a remarkable emergent property that offers potential for resilience in collapse. As the system comes apart, humanity will increasingly rely on informality for survival. Yet, we have shown that informality is a significant factor in sustaining the overshoot of the conservation phase, and may not be a sustainable solution to the problems we face. We also question if a release phase informality will bear resemblance to the community social scientists now theorize, and if the terms of its existence are even possible in a post-conservation phase world.

\section{Notes}

1. We note that Duit and Galaz (2008) have made what we see as somewhat parallel arguments about how complex adaptive systems might develop systems of governance. Space considerations do not allow us to tease out the nuances of the similarities and differences between their approach and ours. Indeed, that is a task that might best be left scholars other than ourselves or Duit and Galaz.

2. For two early world-system comments on the relations between the worldsystem and ecosystems see Bergesen (1995a, 1995b). For a recent compendium on world-systems analysis, globalization, and the environment, see Jorgensen and Kick (2006).

Glen David Kuecker is an associate professor of Latin American history at DePauw University, Greencastle, Indiana, where he also holds a University Professorship, 2008-2012. He earned his Ph.D. in Latin American and global history at Rutgers University, New Brunswick, New Jersey. Professor Kuecker is co-founder of the Canary Institute (canaryinstitute.org), and conducts collaborative research with Globalism Research Center, RMIT University, Melbourne. He is co-editor of Latin American Social Movements in the Twenty-first Century: Resistance, Power, and Democracy (Rowman and Littlefield, 2008). E-mail: gkuecker@depauw.edu.

Thomas D. Hall is professor emeritus at DePauw University, Greencastle, Indiana, Department of Sociology and Anthropology). He holds an M.A. in Anthropology from the University of Michigan and a Ph.D. in Sociology from the University of Washington. His interests include indigenous peoples, pastoral nomads, ethnicity, world-systems analysis, globalization, comparative frontiers, and long-term change. He is coauthor with James V. Fenelon of Indigenous Peoples and Globalization: Resistance and Revital- 
ization (2009, Paradigm Press). A recent article on comparative frontiers is "Puzzles in the Comparative Study of Frontiers: Problems, Some Solutions, and Methodological Implications." Journal of World-Systems Research 15:1: 25-47. He is book review editor for Journal of World-Systems Research.

\section{Acknowledgements}

We thank the editors, Sing C. Chew and Matthias Gross, and our anonymous reviewers for useful and insightful comments. We also thank those scholars who heard early versions of this paper and offered useful comments, especially students and faculty at various sustainability discussions at DePauw University. As ever, remaining errors are ours.

\section{References}

Agyeman, Julian. Sustainable Communities and the Challenge of Environmental Justice. New York: New York University Press, 2005.

Aída Hernández Castillo, R., and Shannan Mattiace, eds. 2003. Mayan Lives, Mayan Utopias: The Indigenous People of Chiapas and the Zapatista Rebellion. New York: Rowman and Littlefield.

Albert, Michael. 2003. Parecon: Life After Capitalism. New York: Verso.

Anderson, Sherry Ruth, and Paul Ray. 2000. The Cultural Creatives: How 50 Million People are Changing the World. New York: Three Rivers Press.

Arato, Andrew, and Jean Cohen. 1992. Civil Society and Political Theory. Cambridge, MA: MIT Press.

Bacon, David. 2008. Illegal People: How Globalization Creates Migration and Criminalizes Immigrants. Boston: Beacon Press.

Bauman, Zygmunt. 2001. Community: Seeking Safety in an Insecure World. Cambridge: Polity Press.

Bergesen, Albert J. 1995a. "Eco-Alienation." Humboldt Journal of Social Relations 21:1-14.

Bergesen, Albert J. 1995b. "Deep Ecology and Moral Community." Pp. 193-213 in Rethinking Materialism: Perspectives on the Spiritual Dimension of Economic Behavior, edited by Robert Wuthnow. Grand Rapids, MI: Erdmanns.

Berry, Thomas. 1988. The Dream of the Earth. San Francisco: Sierra Club Books.

Bodley, John H. 2003. Power of Scale: A Global History Approach. Armonk, NY: Sharpe.

Brown, Lester. 2006. Plan B 2.0: Rescuing a Planet under Stress and a Civilization in Trouble. New York: W. W. Norton.

Carr, Mike. 2004. Bioregionalism and Civil Society: Democratic Challenges to Corporate Globalism. Vancouver: University of British Columbia Press.

Chase-Dunn, Christopher. 1988. "Comparing World-Systems: Toward a Theory of Semiperipheral Development." Comparative Civilizations Review 19: 29-66.

Chase-Dunn, Christopher. 1990. "Resistance to Imperialism: Semiperipheral Actors." Review 13 (1): 1-31.

Chase-Dunn, Christopher, and Thomas D. Hall. 1997. Rise and Demise: Comparing World-Systems. Boulder: Westview Press. 
Chew, Sing C. 2002. "Globalization, Dark Ages and Ecological Degradation." Global Society 16: 333-356.

Chew, Sing C. 2005. "Dark Ages, Hegemonial Shifts, and Environmental/Climactic Changes, 2200 B.C.-700 B.C." Pp. 52-74 in The Historical Evolution of WorldSystems, eds. Christopher Chase-Dunn and E. N. Anderson. London: Palgrave.

Chew, Sing C. 2007. The Recurring Dark Ages: Ecological Stress, Climate Changes, and System Transformation. Lanham, MD: Altamira Press.

Chew, Sing C. 2008. Ecological Futures: What History Can Teach Us. Lanham, MD: AltaMira Press.

Clark, Robert. 2002. Global Awareness: Thinking Systemically About the World. New York: Rowman and Littlefield.

Cohen, Jeffrey. 2004. The Culture of Migration in Southern Mexico. Austin: University of Texas Press.

Cross, John. 1998. Informal Politics: Street Vendors and the State in Mexico City. Stanford, CA: Stanford University Press.

Cross, John. 2000. "Street Vendors, and Postmodernity: Conflict and Compromise in the Global Economy." International Journal of Sociology and Social Policy 20 (1/2): 29-51.

Davis, Mike. 1998. Ecology of Fear: Los Angeles and the Imagination of Disaster. New York: Vintage Books.

Davis, Mike. 2006. Planet of Slums. New York: Verso.

Delanty, Gerad. 2010. Community. Second Edition. London: Routledge.

De Soto, Hernando. 1989. The Other Path: The Invisible Revolution in the Third World. New York: Harper and Row.

Díaz-Polanco, Hector. 1997. La rebelión Zapatista y la autonomía. Mexico City: Siglo Veintiuno Editores.

Duit, Andreas, and Victor Galaz. 2008. "Governance and Complexity_Emerging Issues for Governance Theory." Governance: An International Journal of Policy, Administration, and Institutions 21:3(July): 311-335.

Durand, Jorge, Nolan J. Malone, and Douglas Massey. 2002. Beyond Smoke and Mirrors: Mexican Immigration in an Era of Economic Integration. New York: Russell Sage Foundation.

Escobar, Arturo. 1995. Encountering Development: The Making and Unmaking of the Third World. Princeton: Princeton University Press.

Esteva, Gustavo. 1999. "The Zapatistas and People's Power." Capital and Class 68: 153-182.

Esteva, Gustavo, and Madhu Suri Prakash. 1998. Grassroots Post-Modernism: ReMaking the Soils of Cultures. New York: Zed Books.

Fenelon, James, and Thomas Hall. 2008. "Revitalization and Indigenous Resistance to Globalization and Neo-liberalsim." American Behavioral Scientist 20 (10): 18671901.

Fox, Jonathan. 2005. "Unpacking Transnational Citizenship." Annual Reviews in Political Science 8: 171-201.

Friedmann, John. 1987. Planning in the Public Domain. Princeton: Princeton University Press.

Friedmann, John. 1992. Empowerment: The Politics of Alternative Development. Cambridge, MA: Blackwell. 
Friedmann, John. 1998. "The New Political Economy of Planning: The Rise of Civil Society." Pp. 19-35 in Cities for Citizens: Planning and the Rise of Civil Society in a Global Age, eds. Mike Douglas and John Friedmann. New York: John Wiley and Sons.

Friedman, Thomas. 2000. The Lexus and the Olive Tree. New York: Random House.

Friedman, Thomas. 2008. Hot, Flat, and Crowded: Why We Need A Green Revolution-and How it Can Renew America. New York: Farrar, Straus and Giroux.

Friedman, Thomas. 2009. "The Inflection is Near." New York Times. March 8.

Fukuyama, Francis. 1989. "The End of History." The National Interest. Pp. 3-18.

Gaughan, Joseph, and Louis A. Ferman. 1987. "Toward an Understanding of the Informal Economy." Annals of the American Academy of Political and Social Science 493: 15-25.

Gunderson, Lance, and Clawrence S. Holling. eds. 2002. Panarchy: Understanding Transformations in Human and Natural Systems. Washington, DC: Island Press.

Hale, Charles. 2004. "Rethinking Indigenous Politics in the Era of the 'Indio Permitido."” NACLA: Report on the Americas. (September/October): 16-21.

Hall, Thomas D., and James V. Fenelon. 2004. "The Futures of Indigenous Peoples: 9-11 and the Trajectory of Indigenous Survival and Resistance." Journal of WorldSystems Research 10 (1): 153-197.

Hall, Thomas D., and James V. Fenelon. 2008. "Indigenous Movements and Globalization: What is Different? What is the Same?" Globalizations 5 (1): 1-11.

Hall, Thomas D., and James V. Fenelon. 2009. Indigenous Peoples and Globalization: Resistance and Revitalization. Boulder: Paradigm Press.

Hart, Keith. 1970. "Small Scale Entrepreneurs in Ghana and Development Planning." Journal of Development Studies 6: 104-120.

Hart, Keith. 1973. "Informal Income Opportunities and Urban Employment in Ghana." Journal of Modern African Studies 11: 61-89.

Henry, Stuart. 1987. "The Political Economy of Informal Economies." Annals of the American Academy of Political and Social Science 493: 137-153.

Hernández Navarro, L., and R. Vera Herrera, eds. 1998. Acuerdos de San Andrés. Mexico City: Ediciones Era.

Homer-Dixon, Thomas. 2006. The Upside of Down: Catastrophe, Creativity, and the Renewal of Civilization. Washington, DC: Island Press.

Illy, Hans. 1986. "Regulation and Evasion: Street-Vendors in Manila." Policy Sciences 19 (1): 61-81.

Inda, Jonathan Xavier. 2006. Targeting Immigrants: Government, Technology, and Ethics. Malden, Ma.: Blackwell Publishing.

International Labor Office. 1972. Employment, Income and Equality: A Strategy for Increasing Productivity in Kenya. Geneva: ILO.

Johnson, Steven. 2001. Emergence: The Connected Lives of Ants, Brains, Cities, and Software. New York: Touchstone/Simon and Schuster.

Jorgenson, Andrew, and Edward Kick, eds. 2006. Globalization and the Environment. Leiden: Brill (republished by Haymarket Press, Chicago, IL 2009).

Kardulias, P. Nick. 2007. "Negotiation and Incorporation on the Margins of WorldSystems: Examples from Cyprus and North America." Journal of World-Systems Research 13 (1): 55-82. 
Korten, David. 1999. The Post Corporate World: Life After Capitalism. West Hartford, CT: Kumarian Press.

Korten, David. 2006. The Great Turning: From Empire to Earth Community. Bloomfield, CT: Kumarian Press.

Kuecker, Glen. 2004. "Latin American Resistance Movements in the Time of the Posts." History Compass 2: 1-27.

Kuecker, Glen. 2007. "The Perfect Storm: Catastrophic Collapse in the 21 st Century." The International Journal Of Environmental, Cultural, Economic And Social Sustainability 3 (5): 1-10.

Kuecker, Glen, Martin Mulligan, and Yaso Nadarajah. 2010. "Turning to Community in Times of Crisis: Globally Derived Insights on Local Community Formation." Community Development Journal. Doi: 10.1093/cdj/bsq002.

Kuecker, Glen, Richard Stahler-Sholk, and Harry Vanden. 2008. Latin American Social Movements in the Twenty-first Century: Resistance, Power, and Democracy. Lanham, MD: Rowman and Littlefield.

Loeb, Paul Rogat. 1999. Soul of a Citizen: Living With Conviction in a Cynical Time. New York: St. Martin's Griffin.

Massey, Doreen. 2005. For Space. London: Sage.

Mattiace, Shannon. 2003. To See with Two Eyes: Peasant Activism \& Indian Autonomy in Chiapas, Mexico. Albuquerque: University of New Mexico Press.

McKibben, Bill. 2007. Deep Economy: The Wealth of Communities and the Durable Future. New York: Henry Holt and Company.

Meadows, Dennis, Donella Meadows, and Jorgen Randers. 2004. Limits to Growth: The 30-Year Update. White River Junction, VT: Chelsea Green Publishing Company.

Pickering, Kathleen Ann. 2000a. Lakota Culture, World Economy. Lincoln, NE: University of Nebraska Press.

Pickering, Kathleen Ann. 2000b. "Alternative Economic Strategies in Low-Income Rural Communities: TANF, Labor Migration, and the Case of Pine Ridge Indian Reservation." Rural Sociology 65 (1): 148-167.

Putnam, Robert. 2000. Bowling Alone: The Collapse and Revival of American Community. New York: Simon and Schuster.

Robinson, William. 2004. A Theory of Global Capitalism: Production, Class, and State in a Transnational World. Baltimore: Johns Hopkins University Press.

Robinson, William. 2008. Latin America and Global Capitalism: A Critical Globalization Perspective. Baltimore: The Johns Hopkins University Press.

Rose, Nikolas. 1996. "The Death of the Social." Economy and Society 25 (3): 327356.

Rose, Nikolas. 2008. "The Death of the Social?: Refiguring the Territory of Government." In Peter Miller and Nikolas Rose (eds). Governing the Present: Administering Economic, Social and Personal Life. Cambridge, UK: Polity Press.

Salt, David, and Brian Walker. 2006. Resilience Thinking: Sustaining Ecosystems and People in a Changing World. Washington, DC: Island Press.

Salter, Mark. 2008. "When the Exception Becomes the Rule: Borders, Sovereignty, and Citizenship." Citizenship Studies 12 (4): 365-380.

Sen, Amartya. 1999. Development as Freedom. New York: Anchor Books. 


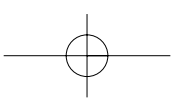

GLEN DAVID KUECKER AND THOMAS D. HALL

Slater, David. 2004. Geopolitics and the Post-colonial: Rethinking North-South Relations. Oxford: Blackwell Publishing.

Stephen, Lynn. 2007. Transborder Lives: Indigenous Oaxacans in Mexico, California, and Oregon. Durham, NC: Duke University Press.

Taylor, Mark. 2001. The Moment of Complexity: Emerging Network Culture. Chicago: University of Chicago Press.

Waldrop, M. Mitchell. 1992. Complexity: The Emerging Science at the Edge of Order and Chaos. New York: Simon and Schuster.

Wallerstein, Immanuel. 1998. Utopistics: Or, Historical Choices of the Twenty-First Century. New York: The New Press.

Wilmer, Franke. 1993. The Indigenous Voice in World Politics: Since Time Immemorial. Newbury Park: Sage.

Zlolniski, Christian. 2006. Janitors, Street Vendors, and Activists: The Lives of Mexican Immigrants in Silicon Valley. Berkeley: University of California Press. 